\title{
PERUBAHAN BUDAYA ORGANISASI DARI UNIVERSITAS PEMBELAJARAN KE UNIVERSITAS PENELITIAN DI UNIVERSITAS LAMPUNG
}

\author{
Feni Rosalia, dan Lilih Muflihah \\ Fakultas Ilmu Sosial dan Ilmu Politik, Universitas Lampung, Jl. Soemantri Brojonegoro No. 1, Bandar Lampung \\ E-mail: feni.rosalia@fisip.unila.ac.id
}

\begin{abstract}
ABSTRAK. Universitas Lampung (Unila) berproses dari Universitas Pembelajaran ke Universitas Penelitian, namun masih mengalami kendala dalam jumlah penelitian dan publikasi penelitian. Untuk menjadi Universitas Penelitian Unila dituntut untuk menyediakan keunggulan kompetitif yang strategis terkait budaya meneliti. Tujuan yang ingin dicapai dalam penelitian ini adalah mengetahui budaya organisasi di Unila serta mengetahui proses perubahan budaya, dari Universitas Pembelajaran kepada Universitas Penelitian. Metode yang digunakan dalam penelitian ini adalah kuantitatif dengan statistik inferensi karena penelitian ini bertujuan untuk mengetahui berbagai variasi yang muncul dari perubahan budaya organisasi dari universitas pembelajaran ke universitas penelitian. Populasi dalam penelitian ini adalah Tenaga Pendidik Universitas Lampung, dengan sampel berjumlah 90 orang. Teknik pengumpulan data yang digunakan adalah kuisioner. Teknik analisis data menggunakan analisis univariat (analisis per variabel) dan analisis bivariat (analisis dua variabel). Hasil penelitian menunjukkan bahwa budaya organisasi Universitas Lampung sudah mengarah pada perubahan budaya dari Universitas Pembelajaran ke Universitas Penelitian. Namun budaya riset yang terbangun masih bersifat personal, karena kebutuhan pribadi bukan digerakkan secara masif oleh perguruan tinggi. Hal tersebut dapat dilihat dari komparasi antara manajemen perguruan tinggi dan budaya riset. Prakarsa dan konsistensi didominasi oleh keinginan pribadi dan publikasi belum membudaya akibat lemahnya dosen menjangkau akses kepada publikasi tersebut. Saran penelitian adalah komitmen pemimpin yang tinggi, baik dari kebijakan yang dikeluarkan dan dukungan pendanaan, sarana dan prasarana. Budaya research tidak hanya mementingkan personal saja tetapi research dilaksanakan secara kelembagaan dan diyakini sebagai kebutuhan bersama.
\end{abstract}

Kata kunci: budaya; universitas pembelajaran; universitas penelitian

\section{CHANGE IN ORGANIZATIONAL CULTURE FROM TEACHING UNIVERSITY TO RESEARCH UNIVERSITY AT LAMPUNG UNIVERSITY}

\begin{abstract}
University of Lampung (Unila) is one of the State Universities in Indonesia that has a vision to be 10 (ten) best universities in Indonesia in 2025. From Teaching University to Research University, Unila is required to have a clear organizational culture. As an organization, in carrying out, Unila activities cannot be separated from the change of culture. If it leads to a culture of research, Unila is required to provide a strategic competitive advantage related to the culture of the research. Unila should expand researches or scientific publications to get to Research University. The goal to be achieved in this research is to know the organizational culture in Unila and to know the process of cultural transformation, from Teaching University to Research University. The method used in this study is quantitative descriptive because this study aims to explain the various conditions, situations, or variables arising from the object of research. Population and sample in this research are Lampung University Lecturers. Data collection techniques are questionnaires. Data analysis technique using univariate (per variable analysis) and bivariate analysis (two variables analysis) obtained from the result of questionnaire. The results showed that the organizational culture of the University of Lampung has led to cultural changes from teaching University to research University. However, the changes have not been reached maximally, because the organizational culture in terms of leadership, policies, facilities, infrastructures, and funding are still experiencing many obstacles. Although the research culture of lecturers is not yet comprehensive, it is limited to only a few faculties. The research team recommended the change of organizational culture as the spearhead of maximum research culture at the Lampung University.
\end{abstract}

Keywords: culture, teaching university, research university

\section{PENDAHULUAN}

World Class University (WCU) adalah pengakuan internasional bagi Perguruan tinggi. Kriteria dapat diakui sebagai WCU diantaranya adalah karya penelitian dosen, baik dalam aspek publikasi karya ilmiah pada jurnal-jurnal yang dibaca dan dikutip oleh akademisi mancanegara, jumlah kutipan, pendapatan universitas dari penelitian inovatif untuk membantu dunia industri, baik penelitian evaluatif, pengembangan maupun penelitian untuk temuantemuan inovasi baru baik dalam aspek teknologi, sistem maupun manajemennya. Untuk dapat bersaing di tingkat global PT harus menjadi research university, yaitu universitas yang memiliki misi memperbesar jumlah penelitian, dengan perluasan pada seluruh bidang ilmu dan kerjasama dengan industri, serta memperbesar jumlah alumni graduate studies, baik pada jenjang program magister maupun doktor. Universitas riset berfokus pada penelitian. Produktivitas penelitian lebih mudah diukur dari pada jenis pekerjaan akademis lainnya, dan publikasi dan ranking merupakan bagian kecil dari sistem akademik. (Altbach, 2015:6). Bersamaan dengan itu, universitas juga mengurangi jumlah dan volume mahasiswa pada program sarjana (Shaugnessy, 2011). Universitas dituntut dituntut memiliki sumber daya yang handal. Kemampuan melakukan penelitian dan pengembangan 
ilmu dan pendidikan pengajaran yang dicirikan tingginya kemampuan dalam:

a. Membimbing mahasiswa dalam kegiatan seminar mahasiswa laporan ilmiah, pembuatan makalah serta kegiatan akademik lainnya.

b. Merancang dan mengadakan penelitian baik secara kelompok maupun mandiri

c. Membuat laporan karya ilmiah ataupun penelitian secara tepat berdasarkan syarat ilmiah

d. Menyajikan karya tulis dalam diskusi ilmiah, seminar jurusan, fakultas, regional maupun tingkat nasional internasional

e. Membimbing penelitian mahasiswa

f. Mengkaji bahan-bahan ilmiah mutakhir seperti hasil hasil penelitian. (Setiawati, 2009:4)

Pada konteks PT di Indonesia sebagian besar PT mengadopsi sebagai Universitas Pembelajaran atau Teaching University. Banyak Universitas di Indonesia memiliki program doktor/S-3 tapi masih berfokus pada pada pembelajaran lanjutan program tingkat sarjana, padahal sangat potensial dikembangkan menjadi research university. Banyak karya ilmiah atau hasil penelitian hanya sebatas seminar dan prosiding dan tidak dipublikasikan ke jurnal nasional atau jurnal internasional. Universitas Lampung (Unila) sebagai salah satu Perguruan Tinggi Negeri di Indonesia melalui visi menjadi 10 (sepuluh) perguruan tinggi terbaik di Indonesia pada tahun 2025 berkomitmen untuk bertransformasi dari teaching university kepada research university.

Hasil evaluasi Diri Unila tahun 2016 (Unila dalam angka, 2016) menunjukkan bahwa kelemahan Unila dalam penelitian adalah banyaknya dosen Unila tidak mempublikasikan hasil penelitiannya di dalam jurnal Internasional Terakreditasi. Walaupun tahun 2016 Unila sudah mempublikasikan hasil penelitian di Jurnal Internasional terindektasi mencapai 45 artikel, dan menempatkan Unila di posisi ke 17 dari 50 institusi PT/PTN dalam produktivitas jurnal indeks scopus. Hal ini masih jauh di bandingkan dengan PT yang berada di Pulau Jawa seperti UI, UNPAD dan UGM yang rata-rata mempublikasikan hasil penelitiannya lebih dari 50 judul ke jurnal internasional terakreditasi.

Dalam perspektif manajemen strategik, problem ketertinggalan Unila dengan PT di Jawa dapat dikurangi, karena berdasarkan evaluasi dari Kemenristekdikti tahun 2016 pencapaian visi Unila menempati posisi peringkat ke 22 dari lebih dari 3000 PT di Indonesia. Pada tahun 2016 Unila memperoleh akreditasi institusi dengan predikat A. Unila saat ini memiliki SDM yang yang berkualitas, profil mahasiswanya sangat beragam, dan memiliki brand image sebagai PT yang berkelas khususnya di luar Pulau Jawa. Menurut data Unila dalam angka tahun 2016, tahun akademik 2014-2015 jumlah dosen sebanyak 1.158 dan memiliki rasio dosen dan mahasiswa sudah ideal yaitu 1:20,7. Jumlah dosen tetap di Unila 30\% bergelar S-3, 65\% bergelar S-2, dan 5\% bergelar S-1 (sedang menempuh S-2) selain itu asal mahasiswa/wi yang kuliah di Unila sudah tersebar dari 33 provinsi yang ada di Indonesia. Berdasarkan data di atas menunjukkan bahwa selain kekurangan yang ada, ternyata Unila memiliki kelebihan sebagai faktor pendukung research university.

Untuk mewujudkan PT berskala research university diperlukan perubahan pola pikir perguruan tinggi yang berorientasi pada penciptaan suatu budaya organisasi yang lebih dinamis, kompetitif, dan produktif. Budaya organisasi di perguruan tinggi menggambarkan hubungan lingkungan yang memberikan pengaruh atau efek bagi seluruh civitas akademika yang ada pada perguruan tinggi tersebut baik itu mahasiswa, dosen serta karyawan. Budaya organisasi perguruan tinggi merupakan kepercayaan dan perilaku yang dikerjakan seluruh civitas akademika yang ada pada perguruan tinggi tersebut dan diyakini. bersamasama membentuk organisasi dan menentukan batasanbatasan di dalamnya. Budaya organisasi perguruan tinggi merupakan pemahaman dan kesepakatan antara komponen yang ada pada perguruan tinggi tersebut yang membentuk respon terhadap tuntutan internal dan eksternal. Budaya organisasi terefleksikan pada perencanaan, kerjasama, komunikasi, pelatihan dan pengembangan, imbalan, pengambilan keputusan, pengambilan resiko, praktik manajemen, motivasi bekerja, keikhlasan, disiplin dan menghargai waktu, semangat egalitarian, dan ketertiban dalam melaksanakan beribadah terhadap kinerja dosen yang terefleksikan pada kegiatan pendidikan dan pengajaran, penelitian dan pengabdian pada masyarakat, serta kegiatan penunjang. (Sangadji, 2009:64). Unila terus berkembang dan harus mempertahankan posisi organisasi dalam jangka waktu yang lama. Untuk bertransformasi dari Teaching University ke Research University Unila harus memiliki budaya organisasi yang jelas. Jika mengacu pada visi Unila menjadi research university maka budaya organisasi Unila sudah selayaknya mengarah pada budaya yang mendukung pencapaian Research University.

Budaya Organisasi di perguruan tinggi harus unik dan sesuai dari organisasi tersebut agar budaya organisasi tersebut tidak sama dan tidak dapat diduplikasi oleh organisasi yang lain serta menjadi ciri khas dari suatu organisasi tersebut. Budaya organisasi harus mendorong anggota untuk bekerja. Budaya organisasi yang kurang memotivasi atau mendukung karyawannya akan menurunkan kinerja karyawan (Sulistyaningsih, 2012:100). Budaya organisasi akan menumbuhkan komitmen kerja. Komitmen kerja meliputi kesungguhan dalam melaksanakan pekerjaan, adanya kemauan untuk bekerja lebih baik, loyalitas terhadap organisasi, dan kepatuhan terhadap nilai dan tujuan organisasi. (Sudiro, 2009:90). 
Berdasarkan latar belakang masalah, maka pertanyaan penelitian ini adalah: (1) Bagaimanakah budaya organisasi di Universitas Lampung? dan(2) Bagaimanakah variasi budaya dalam proses transformasi dari teaching university ke research university di Universitas Lampung?

\section{METODE}

Penelitian ini menggunakan tipe penelitian kuantitatif dengan statistik inferensi karena penelitian ini bertujuan untuk mengetahui berbagai variasi yang muncul dari perubahan budaya organisasi dari universitas pembelajaran ke universitas penelitian. Penelitian dilaksanakan di Universitas Lampung. Alasan pemilihan lokasi karena Universitas Lampung memiliki visi menjadi 10 (sepuluh) perguruan tinggi terbaik di Indonesia pada tahun 2025. Berdasarkan Unila dalam angka tahun 2017, Universitas Lampung memiliki SDM dengan jumlah memadai (1107 tenaga pendidik dan 613 tenaga kependidikan, dengan pendidikan tenaga pendidik jenjang S2 dan S3 sebanyak 1071 orang. Jumlah mahasiswa peminat Unila pada tahun akademik 2017/2018 adalah 70.465 dengan daya tampung hanya 7854 orang. Profil mahasiswa juga beragam dari berbagai provinsi Indonesia. Penelitian ini memiliki variabel budaya organisasi dan reseach university dengan indikator budaya organisasi dalam konteks manajemen Perguruan Tinggi meliputi: Visi misi Perguruan Tinggi, Kepemimpinan (komitmen pemimpin), Kebijakan Perguruan Tinggi, Fasilitas/sarana prasarana, dan Pendanaan. Sementara indikator budaya riset (research university) meliputi: Prakarsa/cipta, Mitra kerjasama, Konsistensi dan independensi, Regenerasi, Sarana, dan Publikasi.

Populasi penelitian ini adalah seluruh dosen Universitas Lampung pada tahun 2017 yang tidak sedang menempuh pendidikan. Jumlah dosen 1107 orang (Unila dalam angka, 2017), dan yang sedang menempuh pendidikan dalam dan luar negeri 154 orang, sehingga total populasi adalah 953 orang $(\mathrm{FEB}=89 ; \mathrm{FH}=83$; FKIP $=184 ; \mathrm{FP}=2 \mathrm{FK}=48$ ).

Selanjutnya penentuan jumlah sampel diambil dengan rumus slovin,

$\mathrm{N}$

$$
\mathrm{n}=\mathrm{N}\left(\begin{array}{l}
\alpha \\
2
\end{array}\right)+1
$$

Keterangan:

$\mathrm{N}=$ Jumlah Populasi

$\mathrm{n}=$ jumlah sampel

$\alpha=$ derajat kesalahan

Sampel penelitian berjumlah 90 orang, selanjutnya penarikan sampel dengan teknik stratified random sampling, dengan rumus $\mathrm{i}=\mathrm{N} / \mathrm{n}$, sehingga diperoleh dosen dari setiap fakultas yaitu : $\mathrm{FEB}=8 ; \mathrm{FH}=8$; FKIP
$=17 ; \mathrm{FP}=20 ; \mathrm{FT}=14 ; \mathrm{FISIP}=9 ; \mathrm{MIPA}=9 ; \mathrm{FK}=5$. Pengambilan akhir sampel adalah dengan metode arisan. Teknik pengambilan data dilakukan dengan menggunakan kuesioner tertutup serta menggunakan lima pilihan dalam model skala Likert. Pengukuran dengan skala likert dipilih karena teknik ini dapat diukur sikap, pendapat, dan persepsi dosen yang menjadi sampel.

Dari hasil Likert di buat tabulasi yang kemudian di cari reratanya untuk mengetahui kecenderungan jawaban. Setelah itu disajikan dalam bentuk grafik yang kemudian di analisis.

Untuk keperluan analisis kuantitatif, maka jawaban responden diberi nilai skor : sangat setuju diberi skor 5 , selanjutnya setuju diberi skor 4, kurang setuju 3, tidak setuju 2, dan sangat tidak setuju 1. Analisa univariat untuk mendiskripsikan variabel usia, pendidikan, pekerjaan, tingkat pendidikan, jenis kelamin, dsb. Sedangkan analisa bivariat untuk menganalisis variabel Budaya Organisasi (Manajemen Universitas Lampung) dan Budaya Research. Pengolahan data dari kuisioner selanjutnya dianalisis secara deskriptif sehingga lebih mudah dibaca dan diinterpretasikan.

\section{HASIL DAN PEMBAHASAN}

\section{Manajemen Universitas Lampung}

Budaya organisasi dalam penelitian ini lebih menekankan pada manajemen perguruan tinggi tingkat universitas maupun di tingkat fakultas.

\section{Visi dan Misi Perguruan Tinggi}

Unila dalam Rencana Pembangunan Jangka Panjang (RPJP) Unila 2005-2025 telah ditetapkan visi Unila yaitu: "Pada Tahun 2025 Unila Menjadi Perguruan Tinggi Sepuluh Terbaik di Indonesia.”. Sejalan dengan misi pembangunan pendidikan nasional serta kebijakan Kementerian Pendidikan dan Kebudayaan, Unila telah menetapkan misi dalam RPJP Unila 2005-2015 dan dokumen Renstra 2007-2011 sbb :

1. Menyelenggarakan tridarma PT yang berkualitas dan relevan;

2. Menjalankan tata pamong organisasi Unila yang baik (good university governance);

3. Menjamin aksesibilitas dan ekuitas pendidikan tinggi;

4. Menjalin kerja sama dengan berbagai pihak di dalam dan luar negeri.

Fakultas Ekonomi dan Bisnis (FEB) paling berkomitmen untuk mencapai visi dan misi Unila dengan nilai 4,03. Sementara komitmen FMIPA dan FT untuk mencapai visi dan misi Unila memperoleh nilai 3,94 kemudian FK, FP, FKIP dengan nilai 3,86, dan FISIP dengan nilai 3,72 sedangkan Fakultas Hukum (FH) yang terendah dengan nilai 3,44. Komitmen mencapai 
visi dan misi berpengaruh pada manajemen organisasi, jika komitmen tinggi organisasi cenderung membangun manajamen organisasi yang baik. Pada FEB yang memiliki manajemen yang baik, hampir 90 persen program studi dari tingkat diploma hingga pascasarjana berakreditasi A. FEB juga mendapatkan berbagai ISO dari dalam dan luar negeri.

\section{Kepemimpinan (Komitmen Pemimpin)}

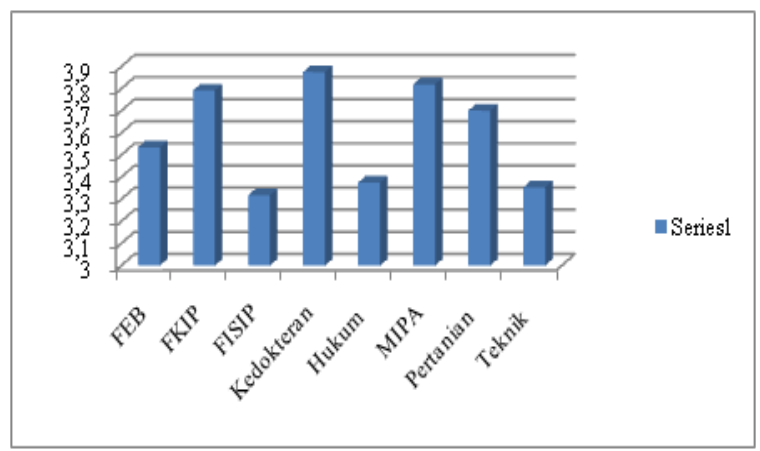

Gambar 1. Kepemimpinan

Cerminan sebuah organisasi salah satunya adalah pemimpin. Komitmen pemimpin menjadi sangat penting dalam manajemen organisasi. Jika pemimpin tidak berkomitmen maka organisasi tidak akan berjalan. Di Univeristas Lampung, Fakultas Kedokteran (FK) memiliki komitmen kepemimpinan tertinggi dengan nilai 3,87. Hal tersebut wajar karena FK merupakan fakultas dengan sumber pemasukan dari mahasiswa tertinggi di Unila sehingga dituntut untuk memberikan yang optimum kepada mahasiswa. FK lebih terkenal terbukti banyaknya peminat, sehingga butuh komitmen kepemimpinan yang tinggi.

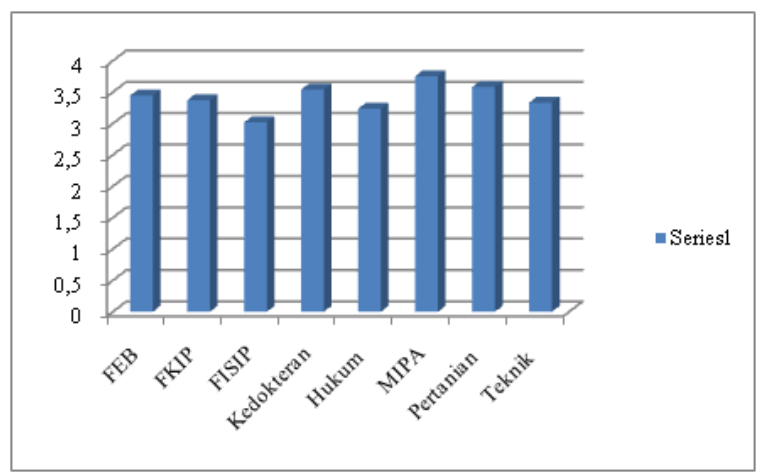

Gambar 2. Kebijakan Perguruan Tinggi

\section{Kebijakan Perguruan Tinggi}

Untuk mencapai visi dan misinya unila membutuhkan aturan main yang kuat dan jelas dalam bentuk berbagai kebijakan. Penerapan kebijakan unila cenderung relatif merata di setiap fakultas, meskipun ada gap tetapi relatif kecil dan tidak terlalu signifikan. Hal ini menunjukkan bahwa semua fakultas di Unila sudah menunjukkan komitmen yang relatif sama untuk menjalankan berbagai kebijakan Universitas Lampung.

\section{Fasilitas/Sarana dan Prasarana}

Pengelolaan keuangan melalui BLU menjadikan universitas mandiri. Sarana dan prasarana menjadi tanggungjawab universitas untuk menjamin proses perkuliahan di kampus. Fakultas bidang ilmu eksakta relatif memiliki sarana dan prasarana yang lebih baik, yaitu FK dengan nilai 3,78 dan FMIPA dengan nilai 3,91. FK memiliki pemasukan dengan nominal yang besar sehingga harus memberikan fasilitas terbaik. FMIPA sebagai pusat bidang eksakta sarana dan prasarananya lengkap khususnya dalam pengadaan dan pengelolaan laboratoriumnya. Namun, fakultas bidang ilmu sosial seperti FISIP dan FH yang masing-masing bernilai 3,15 dan 3,11 cenderung memiliki sarana dan prasarana serta fasilitas rendah. Kemudian FEB 3,61, FKIP 3,45, FP 3,43, dan FT 3,23.

\section{Pendanaan}

Pendanaan berbanding lurus dengan fasilitas, sarana serta prasarana. Semakin tinggi tuntutan fasilitas, sarana dan prasarana maka pendanaan juga semakin tinggi. FK dan FMIPA memiliki pendanaan relatif lebih tinggi dibandingkan dengan fakultas lain, dengan masing-masing nilai 3,77 dan 3,73. Begitu juga dengan FISIP dan FH yang pendanaanya relatif lebih sedikit, dengan nilai 3,18 dan 3,04. Semua pendanaan tergantung fasilitas serta sarana dan prasarana apa yang dibutuhkan oleh setiap fakultas. FEB dengan nilai 3,42, FKIP dengan nilai 3,30, FP 3,27, dan FT 3,1. Secara umum, perbandingan indikator manajemen Universitas Lampung adalah sebagai berikut:



Gambar 3. Perbandingan Manajemen Universitas Lampung

Kepempinan urutan teratas dalam manajemen di Unila, dan berbanding lurus dengan visi misi yang baik di setiap fakultas karena pucuk pimpinan memiliki komitmen yang baik. Ketersediaan sarana dan prasarana juga makin membaik. Namun tingginya kepemimpinan tidak menjamin banyaknya kebijakan yang dibuat, khususnya kebijakan terkait riset.

\section{Budaya Riset Universitas Lampung (Culture Research Lampung University) 1. Prakarsa / Cipta}






Gambar 4. Prakarsa / Cipta

Prakarsa dan cipta berkaitan dengan produktifitas membuat tulisan ilmiah sesuai dengan bidang ilmu. FEB memiliki prakarsa dan cipta tertinggi di unila. Hal tersebut sesuai dengan fakta dengan akreditasi jurusan di FEB yang hampir semua berakreditasi A. FMIPA, FP, dan FT juga memiliki prakarsa dan cipta yang relatif tinggi, karena penelitian-penelitian eksakta peluangnya lebih banyak dan didukung laboratorium yang memadai.

\section{Mitra Riset}

Kecenderungan unik dalam mitra riset yakni FISIP seolah mewakili lmu sosial dan FMIPA mewakili ilmu eksakta. FISIP dengan nilai 4,08 dan FMIPA 4,15. Kedua fakultas melaksanakan berbagai riset baik secara individu maupun bermitra. FMIPA yang memang memiliki lab memadai memiliki mitra riset, tidak hanya melakukan riset secara partnership tetapi pihak dari luar juga bisa menggunakan jasa lab FMIPA untuk riset, hal tersebut saja sudah disebut mitra riset. FISIP dengan kajian ilmu yang luas juga memilki mitra riset yang baik, tidak hanya dalam lingkup lembaga tetapi person to person antara tenaga pengajar. Bahkan karena lingkup ilmu yang luas FISIP memiliki potensi mitra riset yang sangat luas juga tidak terbatas satu daerah saja. Sementara itu FEB dengan nilai 4,03, FKIP 3,61, FK 3,77, FH 3,63, FP 4,01, dan FT 3,94.

\section{Independent dan Konsisten}

Indepedensi dan konsistensi fakultas berbanding lurus dengan komitmen untuk melakukan riset. Fakultas yang memiliki konsistensi dan independensi baik adalah fakultas yang memiliki komitmen riset yang baik, yakni FEB dengan nilai 3,96, FMIPA dengan nilai 3,83, FK dengan nilai 3,93, dan FISIP dengan nilai 3,95. Dalam hal riset keempat fakultas tersebut relatif lebih baik dibandingkan dengan yang lain. Berbanding terbalik dengan FH yang memang komitmen riset fakultas tersebut rendah, berbanding lurus dengan independensi dan konsistensi yang relatif rendah juga, hanya 3,37 .

\section{Regenerasi}

Regenerasi berlangsung baik jika memiliki kerangka dasar yang kuat. Komitmen kepemimpinan berdampak pada tingginya komitmen menajemen organisasi. Komitmen yang tinggi akan mempengaruhi seluruh struktur organisasi. Jika terjadi regenerasi maka tidak akan berdampak apapun pada sistem yang telah bangun. FK dengan nilai 4,09, memiliki regenerasi yang baik karena memiliki komitmen yang sama dari pemimpin hingga anggota paling bawah, regenerasi tidak akan berdampak pada apapun. FH dengan nilai 3,59 memiliki regenerasi yang rendah karena komitmen pemimpin dan manajemennya relatif paling rendah dibandingkan yang lain. Sementara nilai regenerasi FMIPA 4,07, FISIP 4,02, FEB 4,00, FKIP 3,94, FP 3,93, dan FT 3,89.

\section{Sarana Riset}

Sebagai sebuah fakultas dengan jumlah mahasiswa terbanyak di Unila, FKIP memang dituntut memiliki sarana riset yang baik dengan nilai 4,17. Tren sama juga terjadi pada fakultas dengan ilmu eksakta seperti FK dengan nilai 4,00, FMIPA dengan nilai 3,89, dan FP dengan nilai 3,80 yang memiliki sarana riset yang baik dari laboratorium, literarur dan sebagainya. Namun untuk fakultas yang membidangi ilmu sosial seperti FISIP dan FH memang masih memiliki sarana riset yang tidak sebaik dengan eksakta, dengan masing-masing nilai 3,64 dan 3,44. Hal tersebut karena riset ilmu sosial yang tidak terlalu bergantung pada alat riset. Sementara FEB dengan nilai 3,57 lebih rendah sedikit dari FISIP dan FT yang masuk dalam ilmu eksakta namun sarana risetnya hanya 3,44 .

\section{Publikasi}



\section{Gambar 5. Publikasi}

Publikasi ilmiah berbanding lurus dengan cipta dan riset setiap fakultas. FMIPA dan FEB menjadi fakultas dengan publikasi lebih baik dibandingkan yang lain. Publikasi riset FEB dan FMIPA memang lebih produktif karena kedua fakultas sudah mendapatkan ISO dan memiliki jurnal publikasi sendiri. FISIP dan FH sebenarnya memiliki ciptaan riset yang cukup banyak namun memiliki keterbatasan publikasi. Kebanyakan dosen cenderung melakukan mitra riset dan dipublikasikan di luar. FISP dan FH terbatas mempunyai publikasi jurnal yang terakreditasi. 
Secara umum, capaian indikator research university di Unila adalah sebagai berikut:

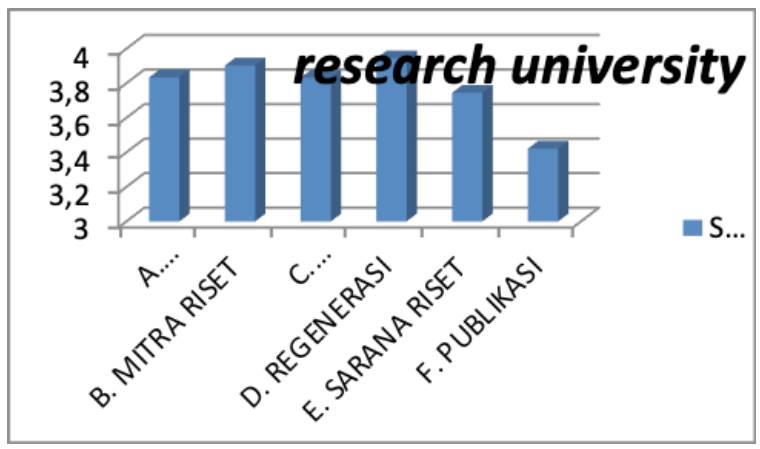

Gambar 6. Research University Universitas Lampung

Regenerasi menempati urutan pertama. Kepemimpinan yang kuat mengakar hingga level bawah, ketika terjadi regenerasi tidak terjadi gejolak. Unila sudah memiliki prakarsa dan cipta yang relatif baik, para stakeholder kampus juga berupaya memperluas jaringan riset dengan memperbanyak mitra riset, menjunjung tinggi asas independensi dan konsistensi. Namun, komitmen dan peluang masih terhambat oleh keterbatasan sarana riset di setiap fakultas terutama fakultas bidang ilmu sosial. Satu yang menjadi kendala adalah tidak adanya saluran publikasi terkareditasi untuk penelitian dosen dan mahasiswa. Ketika komitmen, kreativitas, inovasi mulai berkembang namun tidak ada saluran untuk publikasi tentu membuat beberapa pihak enggan untuk produktif dalam penelitian.

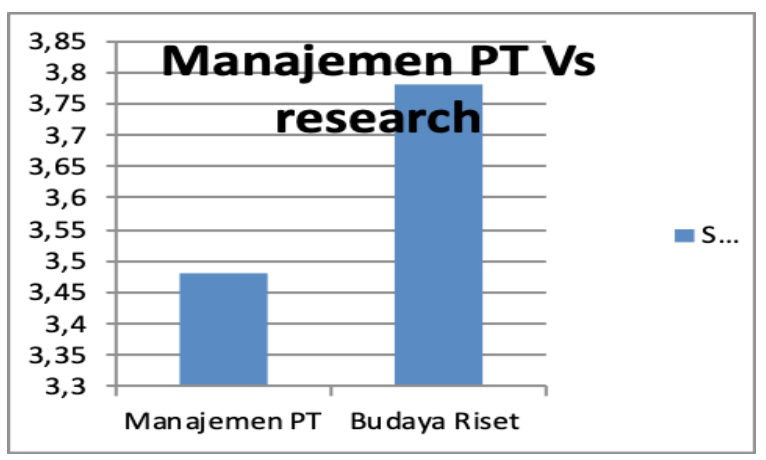

Gambar 7. Manajemen Unila dan Budaya Riset Unila

Universitas Lampung sudah memiliki komitmen untuk menjadi research university, terlihat jelas dari visi dan misi unila yang menggabungkan pendekatan organisasi dan riset. Margin antara Manajemen Perguruan Tinggi dan budaya riset tidak terpaut jauh yaitu hanya sekitar 0.25 poin. Hal tersebut menunjukkan bahwa unila sedang menuju ke arah research university. Namun research university tidak akan terwujud tanpa ada menajemen organisasi yang baik. Oleh karena itu, kesinambungan dan sinergitas antar dua variabel ini menjadi sangat strategis untuk mewujudkan unila sebagai riset university dengan tujuan utamanya adalah mencapai visi dan misi yang telah ditetapkan.

\section{SIMPULAN}

Budaya organisasi berkaitan erat dengan proses menuju research university. Jika ditarik bandul, posisi Universitas Lampung sudah berada di tengah, sudah ada beberapa syarat sebagai research university yang terpenuhi namun ada beberapa hal yang belum dipenuhi dan harus diraih untuk mecapai research university, baik dari sisi manajemen perguruan tinggi maupun budaya research. Budaya riset yang dibangun masih bersifat personal, karena kebutuhan pribadi bukan digerakkan secara masif oleh perguruan tinggi. Hal tersebut dapat dilihat dari komparasi antara manajemen perguruan tinggi dan budaya riset. Prakarsa dan konsistensi didominasi oleh keinginan pribadi dan publikasi belum membudaya akibat lemahnya dosen menjangkau akses kepada publikasi tersebut. Sehingga butuh komitmen pemimpin yang tinggi baik dari kebijakan yang dikeluarkan dan dukungan pendanaan, sarana dan prasarana. Selain itu perlu dimunculkan budaya research peneliti yang tidak hanya mementingkan personal saja tetapi research dilaksanakan secara kelembagaan dan diyakini sebagai kebutuhan bersama, nyaman dan dilakukan secara bersemangat oleh seluruh tenaga pendidik Universitas Lampung.

\section{DAFTAR PUSTAKA}

Altbach, P.G. (2015). What Count for Academic Productivity in Research University? International Higher Education Journal, (79), 6-7.

Sangadji, E.M. (2009). Pengaruh Budaya Organisasi dan Komitmen Organisasional Pimpinan terhadap Kepuasan Kerja dan Dampaknya pada Kinerja. Jurnal Paedagogia, 12, (1), 52-65.

Setiawati, T. (2009). Pengaruh Kompetensi Kerja terhadap Kinerja Dosen. Jurnal Media Pendidikan, Gizi, dan Kuliner, 1, (1), 1-5.

Shaugnessy, Lynn. (2011). What is a Research University. USA: California University.

Sudiro, A. (2009). Pengaruh Komitmen Keorganisasian dan Kepuasan Kerja terhadap Kinerja Tenaga Edukatif/Dosen (Studi di Universitas Brawijaya). Jurnal Aplikasi Manajemen, 7, (10), 86-92.

Sulistyaningsih, Dewi A.S. \& Wijayanti, Y.T. (2012). Pengaruh Budaya Organisasi terhadap Kinerja Karyawan UIN Sunan Kalijaga Yogyakarta. Jurnal Sosiologi Reflektif, 6, (2), 89-101.

Universitas Lampung dalam Angka. (2016). 